ARTICLE

\title{
Conformity in Modern Science: An Engine of Societal Transformation?
}

\author{
Natalia Popova, Yan Moiseenko, Thomas Beavitt \\ Institute for Philosophy and Law, Ural Branch of the Russian Academy of Sciences, \\ Yekaterinburg, Russia
}

\begin{abstract}
The penetration of science into all spheres of life has self-evidently become a contemporary "megatrend". In turn, science itself is also undergoing distinct transformations, e.g., as a result of such processes as increasing regulation and bureaucratisation within academia. In this context, researchers as active producers of scientific knowledge face multiple challenges, including the need to cope with increasing regulation of their everyday practices. Therefore, our research purpose was to investigate the phenomenon of conformity, which, although always having been inseparable from social life, is acquiring a new significance today. Various representations of conformity (e.g. conformist behaviour) have received a great deal of attention from sociologists, biologists and psychologists; however, to our knowledge, there is no generally accepted philosophical understanding of its nature. In this paper, we provide a phenomenological study of conformity on the basis of a comprehensive literature analysis and evaluate its role as a mode of existence in modern science. For the sake of clarity, some illustrations from the everyday lives of researchers are given, including the distribution of the IMRAD format of research articles. Conformity in science is predicted to involve consequences at three distinct levels: (1) within a scientific community, when scientists follow prescribed patterns of conduct; (2) within a particular society when people from all walks of life conform to the standards set by the scientised world-view; and (3) at the global level when non-western communities conform to western standards of life through borrowing western scientific world picture.
\end{abstract}

\section{KEYWORDS}

conformity, conformism, scientism, technological rationality, social institutions, academic science, transformation of academic science, social adaptation mechanisms, phenomenological approach, globalisation 


\section{Introduction}

Although science has long been an important social institution, in recent times it would seem to have become a cornerstone of human social existence. This tendency seems especially pronounced when considering contemporary western societies. In this context, the predominance of scientific discourses can be identified at various levels of involvement, ranging from governmental policy to the everyday being of ordinary people. To an impartial observer, the public sphere might seem to have become obsessed with science, to the extent that any important decision of a political, cultural or educational nature - not to mention different operational decisions in economic and financial fields - can only be taken following a thorough examination of all risks and issues through exacting scientific lenses. Moreover, when examined under the authority of such a scientistic world-view (Feyerabend, 1993), a decision can only acquire the approval of the general public whose rationale conforms to the assumptions according to which this scientistic world-view is constructed. Conversely, irrespective of the applicability of the scientistic approach to the issue for which solutions are to be implemented, the general public is consistently provided with a reinforcing message that the consequences of decisions taken according to non-scientific rationales will prove negative.

Meanwhile, the private sphere of human life has also become captivated by the authority of science, with scientific knowledge actively penetrating and even colonising people's way of life (Salazar \& Bestard, 2015). And, although ordinary people have long relied on science as a tool for acting upon the world and producing certain effects (i.e. in its instrumental aspect), today they are becoming increasingly active themselves in producing scientific knowledge. This phenomenon of research conducted by amateur scientists has even acquired a specific term - citizen science (Cooper, 2016). Thus, whether with direct intellectual effort or the commitment of other resources, people are actively participating in - and, in some cases, contributing to - the development of science. Numerous testaments to such participation, e.g. volunteers gathering data on urban bird behaviours ${ }^{1}$ or carrying out experiments on themselves in the course of their daily lives ${ }^{2}$ can be found on social media networks.

In connection with the abovementioned processes, certain trends in science as a human activity can be observed. One of these may be referred to in terms of a "massification of academic research" (Coccia, 2009): science is no longer an individual endeavour, but increasingly a corporate activity. In terms of the scale and complexity of their organisation, research teams today are starting to resemble medium-size companies (Erzkowitz, 1983; Wuchty \& al., 2007) or quasi-firms, whose employees perform highly differentiated roles. As part of this general trend, for example, it has been shown that the number of authors per paper has nearly doubled (in hard sciences) over the last 50 years (Wuchty \& al., 2007).

Naturally, such science factories cannot function properly in the absence of the necessary bureaucracy - a mechanism, which, according to Max Weber, is inevitably

\footnotetext{
${ }^{1}$ http://blog.nature.org/science/2015/02/17/citizen-science-10-most-popular-projects-best-nature-conservation/

${ }^{2}$ http://www.artofmanliness.com/2012/08/28/how-to-treat-life-like-an-experiment/
} 
associated with increasing organisational size and scope (Weber, 1978). Unfortunately, bureaucracy also entails secondary effects, some of which may negatively impact on its enabling virtues (Crozier, 1964). These side effects, described in terms of bureaucratisation, include inefficiency, rigidity and "bureaucratic entrepreneurism" (Dekker, 2014). Thus, it may be expected that researchers, as active producers of scientific knowledge, will need to find ways to adapt and survive in this new reality.

Anthropologists, sociologists and social psychologists have extensively studied different aspects of adaptive behaviour within large social groups and developed a number of (often contradictory) theories (e.g., Skinner, 1974; Smith, 1992; etc.). Along with such types of behaviour as payoff-based, social approval seeking, etc., conformism is seen as a behavioural strategy selected in over-regulated social environments that feature increasing restrictions and punishments. For example, in his seminal work (Merton, 1938), Robert Merton showed that conformity to goals and means is the "most common and widely diffused" (ibid., p. 673) type of social order in large groups; without such conformity, the continuity of these groups cannot be maintained. Erich Fromm expressed similar ideas in (Fromm, 1965). In extreme cases, when the cultural goal is generated institutionally rather than organically (i.e. from within the group), the conformist behaviour may take the form of ritualism. Under such conditions, "ritualistic adherence to institutionally prescribed conduct becomes virtually obsessive" (Merton, 1938, p. 673).

Despite the phenomenon of conformity and its representations having been extensively studied in the abovementioned disciplines, a philosophical understanding of this phenomenon has yet to be formulated. This is particularly significant, since, considering such trends as the massification of science, the scientisation of life and bureaucratisation, it is reasonable to suppose that conformity will become the dominant mode of existence in science, eventually coming to affect society as a whole. In other words, it can be expected that conformity will become the driver of massive societal transformations.

In response to this, we set out in this work to present a phenomenological understanding of conformity as a social phenomenon. Since this will involve a rather high level of abstraction, we will follow Heidegger's example in presenting a number of illustrations from the everyday life of scientists (viz. his examples of a hammer, cough, fences, etc.). It should be noted that our choice to apply the phenomenological approach is based on Heidegger's claim that only such an approach is capable of grasping a phenomenon in its integrity (Heidegger, 1962).

In order to distinguish our uses of the terms from other possible interpretations, we will now clarify what we mean by conformity and conformism. By conformism, we refer first and foremost to "conformist behaviour", i.e. the concept discussed in social psychology (Ash, 1955). Thus, conformism is seen as a behavioural strategy of imitating the majority, which aims at adjustment to axiological norms and socially accepted conventions shared within a particular group. Conversely, by conformity we understand the underlying phenomenon that generates conformist behaviour. Such a juxtaposition of conformism and conformity demonstrates that conformism is not a self-sufficient social phenomenon. Thus, it is only when considered through the lens 
of the question "What lies behind?" that the phenomenon of conformist behaviour can be seen as a simplified representation of something more ontologically loaded: regardless of the nature of the true phenomenon it represents, conformism turns out to be ontologically rootless and consequently inadequate for phenomenological reinterpretation. Therefore, in what follows, we will focus on the concept of conformity and only refer to conformism when we wish to specifically refer to the set of social behaviours so engendered.

In order to pursue our research aim, the following research questions were formulated:

1. What are the philosophical specifics of the modern scientised world-view, which determine its dominance over other world-views?

2. How can the modern scientised world-view be interpreted from a phenomenological standpoint?

3. Who are the bearers ('Träger' in Heidegger's phenomenological sense) of the modern scientised world-view?

4. What adaptation and coping mechanisms do such bearers demonstrate and what examples of these mechanisms can be found in academic science?

\section{Comprehensive technologisation}

Whether referring to fundamental or applied science, a crucial component of the modern scientistic world-view consists in the priority status allocated to technological development. Thus, applied science employs technologies in an attempt to satisfy the ever-mounting needs of the consumer society and provide higher standards of taken-for-granted everyday comfortableness. At the same time, fundamental science is increasingly becoming reliant on instrumental technologies in order to achieve more and better results (e.g. laser scanning microscopy, infrared spectroscopy, etc.), which, in turn are expected to establish a basis for the development of the knowledge economy. Such technologisation of contemporary science frequently results in the use of specific technologies, which are seen not only as an effective means for achieving short-term goals, but also as permeating all stages of research work - from searching appropriate literature on Internet databases and conducting routine experiments (e.g. genome sequencing) to developing revolutionary approaches intended to shift or replace a dominant paradigm. Moreover, technologies are shown to play an increasingly important role in forming the core set of human cognitive characteristics (Schwab, 2016) that come to shape people's attitude to reality. The embedment of technological systems into the scientific world-view can be captured by the idea of technological rationality, introduced into philosophical and scientific discourses by several German social and political theorists belonging to the Frankfurt School (Horkheimer \& Adorno, 2002; Marcuse, 1982; Marcuse 2002).

In economic terms, the variety of conventional arguments for the unchallenged authority of technological rationality in the area of innovation-based growth could, on the one hand, be easily reduced to the popular notion of progressiveness, taken for the most part as a positive dimension of human orientation to the world. However, it should 
be noted that such an elevation of the status of technology is so readily accepted by researchers not only because of their conformity to the social order and procedural norms, but also because such an understanding of technology has been the result of the prolonged reflection of philosophers on its nature. From this perspective, the philosophical and sociological understanding of technology in the modern era may be seen as having developed through Aristotelian anthropological lenses, with Ernst Kapp interpreting the human body in terms of the pattern of human technological activity (Brey, 2000; Mitcham, 1994) and Alfred Espinas introducing the concept of technology as mature art, a product of human thought and experience that finally gives birth to science as such (Alexandre \& Gasparski, 2000).

Another equally authoritative approach to the essence of technology takes a more pragmatic approach, thus restricting Kapp's anthropomorphism of technique (Mitcham, 1994). The Austrian philosopher Ernst Mach and his Russian populariser Piotr Engelmeier proceeded from the premise that the development of science is influenced by the practical needs of everyday life. Thus, science appears as a faithful servant of humanity, whose duty is to cope with technological challenges (Mitcham, 1994). Consequently, Mach's so-called economy of thought was established within the second approach, while the intellectual activity of a human being here loses the ontological status of technology's root, being reduced to the mere drawing of technical analogies with how technique works in and of itself. As a consequence of such imitation of machines on the part of human beings, a specific anthropological type of human having an engineering mentality was established and encouraged in the Modern era.

Under the conditions of Modernity, the system of technological rationality was deeply embedded not only into scientific, but also social, political and economic spheres, with any philosophical aspects being mostly confined to Marxist and Neo-Marxist discussions. According to Karl Marx, the establishment of technological rationality was a value-neutral result of the historic displacement of hand-labour by productive machine-labour (Marx, 1977). However, the value system of such rationality is always determined by the authorities, who control the means of production, alienating the worker - on the one hand economically, i.e. from the results of what he is producing, and, on the other hand, psychologically, i.e. from the reason why he is producing (Marx, 1977). Neo-Marxist representatives of the Frankfurt School (Horkheimer \& Adorno, 2002; Marcuse, 2002) developed Marx's idea of the capitalist system with its fundamental premise of the social alienation of the worker into the complex critical theory of society. It is significant here that alienation is interpreted not only in terms of the capitalist class having access to modern technologies, which the proletariat lacks, but also through the technologies themselves being engaged into the value-creating process of subduing human nature.

According to Horkheimer and Adorno, humanity's loss of selfhood and immediacy of existence is a consequence of technique (Horkheimer \& Adorno, 2002). It should come as no surprise, then, if the development of technologies becomes a catalyst for the explosion of mass culture in the Modern era. Mass culture inevitably reduces and erodes existing ethical and cultural patterns, thus constituting and distributing globally specific socio-political standards. Socio-political systems based on such standards 
are absolutely syncretic in terms of their axiological priorities and thereby adaptive to any external agency. In a similar manner, the French sociologist and political thinker Jacques Ellul analysed technique as a self-sustaining and independent power that cannot be ignored or belittled, because it imposes itself upon humanity in its function as a specific ideology, as a result, all social, political and economic structures came to be pre-determined by its rigid value system (Ellul, 1964).

The German philosopher Friedrich Jünger also offered a pessimistic prognosis of uncontrolled technologic development. For Jünger, an unrestricted development of technology inevitably leads to a logic according to which human nature becomes something that must be subdued (Jünger, 2010). Thus, in the Modern era an implicit process of devaluation of the human being has become explicit to the extent that any differences between human and technological achievements are becoming increasingly moot. Having previously been interpreted in terms of human activities and skills in the fabrication of goods, under Modernity technologies come not only to dominate the process of producing things, but also to reshape our motivation for developing them. In this way, the remarkable technological achievements of the $20^{\text {th }}$ and $21^{\text {st }}$ centuries have revealed the great power contained within them, one that frames all human problems as due to a lack of societal technologisation and reduces the human being himself/herself to the questions of operational decision-making. Since operations are, by definition, carried out on other things (regardless of whether that thing is a human body in a surgical ward, a mass of earth to be moved, or an enemy capital to be demolished by atom bombs), this is likely to lead to unpredictable and perilous situations ("Technology versus Man", 1949, p. 3).

However, perhaps the most penetrating and powerful philosophical critique of technology, significantly influencing both anthropological and pragmatic (instrumental) approaches, is that developed by the German thinker Martin Heidegger. According to Heidegger, the field of technology encompasses not only the manufacture and utilisation of equipment, tools and machines, but also the entire structure of modern philosophy, which organises itself in such a way as to actively and explicitly serve technological ends (Heidegger, 1977). Heidegger's thought represents a cornerstone of the present research, since it elucidates not only how the Western scientised world-view has come to thoroughly permeate Modernity, but also how the roots of technologised consciousness themselves came into being. However, it is only when analysed through Heideggerian lenses that his ambiguous thesis - "the essence of technology is by no means anything technological" - becomes clear (ibid., p. 4). Moreover, such an understanding may assist in developing an approach that can overcome technological rationality as the idée fixe of modern societies.

\section{Phenomenology of the scientised world-view}

Inasmuch as Heidegger's assertion seems to form the basis for our following analysis of conformity as a mode of existence in modern science, his phenomenological approach towards technologies will be discussed in a twofold manner, with each elucidation serving its own particular purpose. Firstly, a brief review of the historical background 
forming the basis of the essence of technology will be carried out in order to expand our comprehension of the matter beyond conventional understandings, in terms of which the only considered means of rethinking technologies is to discover how to make them more and more technological. Secondly - and this is directly related to the prime objective of the present research - the perspective should be switched from the existence of technologies in and of themselves (as well as from the specific forms shaped by them) and towards the bearers of technologised consciousness.

In contradicting conventional understandings of Modernity as something emergent or self-grounded, the Heideggerian historical purview grounds the scientific and technological age in antiquity. Thus, Heidegger refers to the ancient idea of $\pi$ oinoı (poiesis) - the arising of something from out of itself - as something requiring to be taken into consideration when the genealogy of modern technologies is being considered (Heidegger, 1977, p. 10). The nub of the matter here is that $\pi$ oinoıs, in its bringing-forth capacity, also gives birth to a phenomenon called téxv $\eta$ (techne), implying the bringing into existence of something that did not exist before (ibid.). Therefore, since referring simultaneously to the skill of making a particular thing and

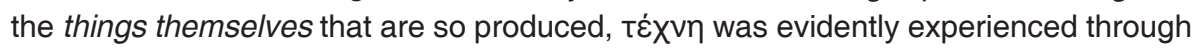
handcraft and labour, i.e. all creative human activities in general along with human intellectual capabilities or so-called arts of mind.

Among those arts of mind, it was philosophy itself that was, for Heidegger, to become a paradigmatic example of $\tau \dot{x} \chi \vee \eta$, while philosophy - being a specific mode of metaphysical thinking - considers a specific reality, i.e. one that duplicates the existence of things themselves. For example, the primary aim of antique philosophy had been to grasp the world in which a person lived in order to reveal whatever could be imperishable within that world, i.e. the essence of all things. In fairness, it must be said that there was no particular mediator implied in the process of comprehension: the

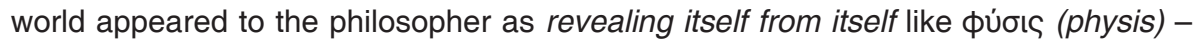
i.e. the self-genesis of nature. As for objective reality, this concept simply did not exist in Pre-socratic philosophy; nevertheless, the roots of Modernity's subject / object dualism can be traced to Plato's philosophy of forms.

Western medieval religious thought represented a reorienting of priorities from revealing the truth of Being towards collaborative strategies for establishing true relationships with God aimed at the assurance of salvation. From a phenomenological viewpoint, medieval philosophy seems to have become overwhelmed in its desperate search for something permanent in human, quotidian existence. Thus, Heidegger finds

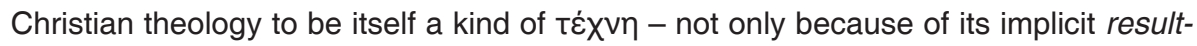
orientation, but also in its establishment of a specific mediator between the human being and the world. How Modernity actually changed this relationship schema, then, was to shift humanity's outlook from a theological to a scientific domain; nevertheless, the same quest for security and permanence was preserved intact.

The fundamentally Modern works of René Descartes and Isaac Newton discovered self-certainty within human reason itself (Descartes, 2004), by means of which the world beyond was substituted, in a philosophical sense, for reality - i.e. in a reflection

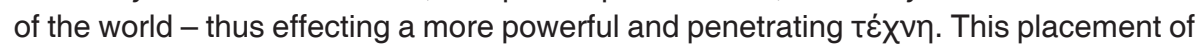


the world of Cartesian objects into a state of dependence on man's mental abilities was deliberate: it is in maintaining such a belief in reality that the subject's self-assurance can be maintained. Having thus become a Cartesian subject - i.e. the dominating centre of reality - man is able to establish the unity of his thinking and being according to the famous formula cogito ergo sum. As a consequence, everything that appears to any human from beyond himself can be shaped, regularised and standardised as a means of satisfying the need for security. However, having been reduced to a construction of the human mind, the world thus finds itself caught in a trap, with no means of escaping from the clutches of that cogito, which only the Cartesian subject is able to provide.

When thus described in terms of subject / object, modern science takes up its by now familiar position to become the means by which $\tau \dot{x} \chi \vee \eta$ can most effectively reinforce itself. Thus, in terms of its teleological consistency, the concern of scientists with investigating the surrounding world seems dispassionate and unchallenged by any alternative form of vónбıৎ (noiesis). However, perhaps the biggest difference between the antique and modern-scientistic philosophical approaches lies in the latter's refusal to permit things to be present as they are. For the former, by contrast, the revelation of things in the truth of authentic Being was the highest value (Heidegger, 1977). Freed of this requirement, modern scientists set about arresting and shackling the world in order to objectify its essence as a "manifold of cause and effect coherences", cleansing it of any hint of pollution by the contingency, eventuality or immediacy of Being. By representing things to himself in this way, the modern scientist makes the world amenable to experiments, with the inherent value of the means-to-an-end factor in any experimental setup advanced as self-evident (ibid., p. 167). For Heidegger, the significance of this idea is revealed precisely when the essence of technology is brought into question, due to the radical departure between anthropological and instrumental interpretations of $\tau \dot{\varepsilon} X \vee \eta$ under Modernity being represented exactly from such a means-to-an-end perspective.

When technologies are bound to a means-to-an-end schema, the ensuing instrumental approach supports human domination over nature; the bringing-forth potential of $\tau \dot{x} X v \eta$-as- $\pi$ oínбıৎ has, by now, been quite forgotten. Nevertheless, even in its modern instrumental interpretation, technology in its essence continues to be a kind of mode of revealing, with only one important specification requiring to be taken into account. As was previously mentioned, the anthropological dimension of

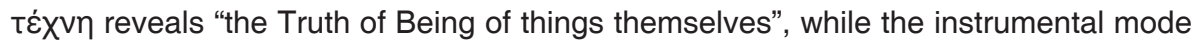
of revealing is also the mode of so-called "challenging revealing" (Heidegger, 1977, p. 16). By conducting scientific experiments on the world of objects in the spirit of "contending with everything that exists", the Cartesian subject appears to exert control over everything he represents and objectifies. Heidegger clarifies his attitude in the following statement: "The revealing that rules throughout modern technology has the character of challenging-forth. Such challenging happens in that the energy concealed in nature is unlocked, what is unlocked is transformed, what is transformed is stored up, what is stored up is, in turn, distributed, and what is distributed is switched about 
ever anew. Unlocking, transforming, storing, distributing, and switching about are ways of revealing that dominate the age of technological Modernity" (ibid., p. 16).

Under this scope, the only relevant quality of things in the world is their readiness for use: the world itself appears as an interconnected network of objects, whose only meaning lies in being available to serve the purpose of "letting-be-controlled" (Heidegger, 1977). Heidegger's special term for describing the phenomenon of undifferentiated availability was "standing-reserve" (ibid., p. 17). The ordering and selfrevealing of everything in terms of standing-reserve is the result of the challenging claim of both people and things occurring in a specific configuration of "ordering for use", i.e. enframing (ibid., p. 19). This characteristic enframing of the essence of technology leads to the second perspective of our analysis - human orientation towards technologies and science, with the concept of the subject now being placed into question. In the next two paragraphs, we will clarify what is meant by enframing in the context of academic science as well as elucidate the question of who is the bearer of the scientised world-view under this framework.

\section{The They as bearer of the scientised world-view}

The essence of technologies is itself not technological, but rather concerns fundamental processes of revealing the truth of Being (Heidegger, 1977). When examined through the lenses of Heidegger's approach, it is human orientation to the world that becomes such an essence; however, both human and the world are now being put into question. Over the centuries, there have been several modes of revealing; within each subsequent paradigm, the mode of revealing has been perverted in an increasingly explicit way due to moving further from its primordial goal. Thus, under the conditions of Modernity, this mode has finally become enframing, previously described as a way of ordering the world in order to capture its essence. In terms of enframing, there is no possibility for the world to be disclosed as itself and from itself; on the contrary, according to one of Heidegger's contemporary interpreters, the world is liable to be disclosed merely as "a valuable material resource to be extracted, expropriated and used-up for whatever man desires or wills of it” (Nadal, 2010).

The most fruitful result of such kinds of instrumental thinking is the creation of different enframings - specific structures and formats, through which different technologies can be used to easily reshape and convert the world into specific forms to be grasped and represented by scientific rationality. Certainly, enframings only complete the process of shifting the concept of the world into the domain of standing-reserve, whereas the question of what the world really is appears to have been left outwith the range of their very concerns. It is at this point that Heidegger makes his famous distinction between ancient and modern philosophies, with the former representing the philosophical world-view and the latter - the scientific world-picture (Heidegger, 1977). Insofar as it is sufficient for introducing the bearer of the modern scientised world-view as well as his mode of existence in science, the distinction between the philosophical world-view and the scientific world-picture should be clearly emphasised. 
World-view could be interpreted as observing-the-world, implying not only the sense of dwelling-within-the-world, but also that the world is not an entity which is a priori given to a human being (Heidegger, 1977). When world-viewing starts from the beyond of nothing, its spontaneous and all-inclusive reflection on the world and on the human being can disclose the universe of their Beings simultaneously: this is considered by Heidegger to be an authentic mode of existence (Heidegger, 1962). According to his thought, world-picture can be understood as having been perverted under a modernistic world-view; however, it should be interpreted as the world grasped as picture, rather than as a picture of the world, implying that such a world is primordially external to a human being. Consequently, it is impossible for any human to $d w e l l$ in such a world - it can only be described or registered as an image or picture by somebody standing apart from it. This mode is claimed by Heidegger to be inauthentic, while in terms of world-picture, the human becomes alienated from the world, resulting in its loss: "Modernity leaves man homeless, without world" (Nadal, 2010).

The Modern scientific world-picture appears to be the most explicit and ambitious example of framework ever constructed; however, its inauthenticity depends not only on a specific understanding of the world (as something to be investigated), but also on a specific understanding of what it means to be human (i.e. that which investigates). In terms of Modernity, "subject" should replace "human", especially when discussing the actor engaged in scientific research. However, here a problem of definition, identified by Heidegger, arises (as a consequence of which the unqualified use of the word "subject" has also been deliberately avoided in the context of our research).

In order to comprehend what is meant by subject in a phenomenological sense, it should be noted that the modern word acquired its meaning from Ancient Greek U "subject" tends to play a much more significant role in contemporary philosophical parlance than merely a synonym for "human": it is only possible to lie-before-something when the being of that-which-lies-before is itself primordial and self-evident to other beings. Conversely, being of the non-human refers to the being of the world; it is only world-picture (world as picture), which can be found in such a dependent relationship on human. In this regard, Heidegger invoked the question of what being in the world really is as well as who is in the world. Having returned to the clear phenomenological understanding that we all are already somewhere in the world, Heidegger introduced his central pre-concept ${ }^{3}$ of Dasein - literally being-there (Heidegger, 1962). In describing a human being in terms of Dasein, Heidegger attempted to escape from the a priori inauthenticity of philosophical notions developed within modern philosophy, especially the juxtaposition of subject and the world of objects. Being already embedded in the world, Dasein itself is prescribed neither as authentic, nor inauthentic; while comprising a new starting point of Heidegger's fundamental ontology, it can exist both in authentic and inauthentic modes (Heidegger, 1962).

In a broad sense, Dasein finds itself as itself proximally and for the most part in its daily existence through its concern with environment. However, complete absorption

${ }^{3}$ Primordial concept. 
into the world of ordinary life experiences, into the world of so-called average everydayness, is fraught for Dasein due to the switching of the inauthentic regime of its existence (Heidegger, 1962). Heidegger suggested this regime to be that of das Man, which can be translated into English as "the They". Heidegger's others must not be interpreted simply as other people; otherwise, the whole logic of his argumentation would be contravened, since other people are always understood within everyday consciousness as other people, but not myself. Having started his analysis from the phenomenon of Dasein, Heidegger maintains that its being-in-the-world is always and at the same time being-with-others, with the generalised character of others already implied in every concern of Dasein with respect to the world (Heidegger, 1962). Moreover, those others are primordial to any particular self, because it is exactly self that is singled out from the others through the switching of the regime of Dasein's existence from inauthentic to authentic - and not the reverse. That is why, in addition to every human being discovering Dasein to be himself/herself, others must also be treated as Dasein, the only proviso being that their existence precedes the first distinction between my own and not my own Dasein.

Nevertheless, others carry the potentiality to become authentic - something that may occur only if Dasein individuates its authentic self from the totality of inauthentic beings. Without this individuation, others remain attached to the They, forming an example of inauthentic self. In terms of average everydayness, where the They exists, several existential characteristics may be detached, including distantiality, averageness and levelling-down (Heidegger, 1962). When discussed in general terms, the They appears to consist in the assembly of different clichés that are predominantly taken for granted as respectable behavioural or intellectual patterns. In other words, the They constrains each Dasein to surrender its uniqueness - and, consequently, its authenticity potential - by following their beaten paths to commonly defined styles of thinking, communicating, writing, etc. Moreover, these paths have been paved not by Dasein, but by the They. Heidegger was clear that "the They, which supplies the answer to the question of the who of everyday Dasein, is the nobody to whom every Dasein has already surrendered itself" [emphasis added] (Heidegger, 1962, p. 166).

Thus, the phenomenological analysis of the essence of technologies provided under these two paragraphs may incline the reader to conclude that the fundamental basis of modern scientific world-picture - i.e. subject / object dichotomy - is by no means something that should be taken for granted. It is only human orientation to the

\footnotetext{
${ }^{4}$ Taking into consideration that this concept of Heidegger seems to be quite complicated, especially in terms of its relation to other philosophical concepts that pre-existed it, the interpretation of das Man should be clarified as a matter of priority. The simplest and briefest explanation of das Man as everyone and no one in particular provides a rough outline of the contours of the concept; however, our preferred English translation of das Man as the They adds an extra dimension to its intrinsic meaning. It should be emphasised that, on the one hand, usage of the They in the singular (i.e. in contradistinction with the plural agreement form used with the pronoun "they") corresponds precisely with the grammatical use of German indefinite pronoun man, from which das Man acquired its currency through nominalisation. On the other hand, the plural sense of das Man is also captured here, which is highly relevant due to Heidegger's assertion of das Man referring first and foremost to the mode of existence of others (Heidegger, 1962).
} 
world that can reshape this topography. We only find the world to consist of objects to be investigated when we consider the world to comprise standing-reserve in its nature as a whole. As soon as we start perceiving objects not as something given to us and human-independent, but as framework-friendly concepts, it is precisely the objectiveness of the world that appears to be challenged. In a similar manner, a human being conducting scientific research has the status of subject only to the extent of being a bearer of scientised consciousness.

When it is understood that it is the consciousness of the They that lies behind the scientised consciousness rather than an individual person, it becomes obvious that scientised consciousness cannot belong to any individual human being. Consequently, the subject, understood as a rationally thinking individual (and bearer of scientised consciousness), immediately becomes an erroneous reference point, because the subjectivity postulated by him or her only serves to deceive us about who he or she really is. After all, subjectivity, by definition, cannot not belong to somebody, however, according to the scientised world-view, it belongs precisely to the They; that is to say, to everybody and nobody. Thus, the very idea of the subject as a certain reference point for a scientific world-view becomes little more than a Potemkin village facade arranged by the They in order to conceal $a \lambda \dot{n} \theta \varepsilon i a$ (alethea) - the truth of Being (Heidegger, 1977).

As a typical example of framework, the modern scientific world-picture is not something rigid and prescribed once and for all; rather, it is dynamic and continually changing within the processes of enframing being initiated by the They. In this regard, the existential characteristics of the They, such as distantiality, averageness and levelling-down, should be elucidated by examples of their practical influence on modern academic science. Conformity as a mode of existence in science should be also introduced, along with the following analysis of adaptation and survival mechanisms applied by modern researchers - i.e. the bearers of the scientised world-picture provided in terms of the societal processes of the scientisation of life and massification of science.

\section{Conformist behaviour in modern science}

As it has been shown in the previous paragraphs, it is the instrumental interpretation of

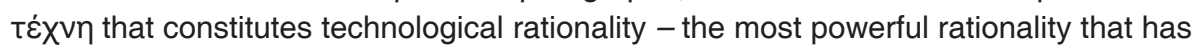
ever existed. Initially conceived as an instrument for use by humanity in transforming the world to make it more comfortable for living in, technological rationality has eventually become an actor in and of itself by organising the world and forcing humanity to submit to its rules. No wonder, then, if the penetration of technologies throughout all spheres of life and provided under its guidance should come to additionally transform human orientation to the world, with enframing acting as the driver of this process. However, the phenomenological analysis of the substitution of the philosophical world-view for the scientific world-picture that occurred during Modernity showed that the two interdependent processes of the scientisation of life and the massification of science involved in establishing the scientised world-view only seem to evolve on 
their own accord. In actuality, it is not just the progressive development of society that determines the contemporary state of affairs in science, but the very manner of thought of the They, which configures the whole structure of human daily existence. Conversely, the phenomenon of conformity is the mode according to which the They gets accustomed to average everyday existence: it would be logical to assume that conformity can express itself in terms of scientific activity and scientific discourse, while in the contemporary world both are explicit examples of enframing in action.

We will now look at some exemplary representations of how the They conducts enframing in order to understand what conformist strategies the bearers of scientised consciousness - i.e. modern researchers - employ in order to adjust to axiological patterns and socially accepted conventions shared within a scientific community. One such illustrative example of how an instrument of convenience eventually became a self-sufficient value can be found in the realm of scientific communication; this is the IMRAD format, which is nowadays used worldwide to present research findings in scientific articles.

The scientific research paper as we know it today has undergone a long evolution (Gross et al., 2002). Initially such texts took the form of letters to colleagues, explaining the details of a study in a narrative style. Then, with the emergence of the first scientific journals and the concomitant need to advance a claim concerning the priority status of communicated knowledge, the scientific text underwent a transformation both in terms of style and composition. Moreover, the professionalisation of the scientific journal brought about the appearance of journal editors, whose mission was to focus articles to meet the interests of other scientists as well as to exclude dilettantes from this increasingly specialised form of communication. The $20^{\text {th }}$ century was marked by an exponential growth in scientific knowledge (Prince, 1963), which also required more efficient means for information exchange and retrieval. Thus, the text composition format acronymised as IMRAD (Introduction, Methods, Results and Discussion) developed from the conventional historical perspective into its current form.

From the phenomenological perspective, the IMRAD format comprises a rigid schema for text production that provides rules for the textual organisation of research articles. For this reason, it may be treated as a typical example of technologisation in academic science. Moreover, IMRAD is not only widely used, but also obligatory in many disciplines, particularly in medicine and the natural sciences; consequently, IMRAD research articles are subject to strong and explicit genre constraints. For example, at the level of the textual surface, the genre constraints can be observed in a linear sequencing of the text, since the format not only prescribes a fixed number of sections, but also the order of their sequencing, regardless of the original vision of the scientific research to be shared within a particular discipline.

It is hardly surprising that in the age of obsessive human relationships with different technologies, the popularity of IMRAD is immense - currently, almost $95 \%$ of all publications in natural sciences journals are presented according to this logic (Popova \& Beavitt, 2017). Moreover, some researchers claim that in medicine this is the only pattern adopted in original papers (Sollaci \& Pereira, 2004). A steadily 
increasing number of journals in social studies and even in humanities insist that authors compose their manuscripts according to international publication standards, which in most cases means adherence to the same IMRAD format. Thus, rather than being an arbitrary option, IMRAD has become not only a standard to which every paper must conform, but also an enframing, which is ostensibly imposed by the They in order to make scientific communication more user-friendly through its reduction to a standardised, depersonalised and generally accepted style.

When IMRAD is seen in terms of enframing, conformity to the rules provided under its guidance becomes a mode of existence. While such a mode is inauthentic due to its belonging to the They, nevertheless, it appears to be justified by the following reasons of convenience, which the They guarantees to any participant in scientific communication:

1. Convenience for authors. The underlying logic of the IMRAD format provides an autological reflection of the scientific research process: the research questions are initially stated, then the necessary tools selected, results captured and relevant conclusions drawn therefrom. Thus, the IMRAD format not only provides rules for the organisation of a text at the macro-level (strict sequence of sections), but also structures the micro-level, i.e. in terms of the order of semantic units. This pattern is disseminated throughout the global academic community in academic writing classes, both at undergraduate and graduate levels. Writing papers in such a manner is particularly convenient for non-native speakers of English, who greatly outnumber natives in contemporary scientific communication.

2. Convenience for readers. According to researchers in cognitive psychology, reading scientific texts is a complicated human activity, multidimensional rather than linear in character (Kintsch, 1998). IMRAD papers facilitate modular reading, because each section of the paper contains information in a semantically preordained manner: e.g., the research question follows the description of the research gap and can normally be browsed by phrases such as "although much research has been carried out to..." or "despite significant progress in..." Linguists have shown that the diversity of semantic "moves and steps" in contemporary IMRAD papers is almost negligible (Swales, 1990; Brett, 1994; Hopkins \& Dudley-Evans, 1988; Kanoksilapatham, 2005). Thus, for an experienced researcher, reading a well-formed English-language scientific article can be commenced from virtually any section, including keywords and title, since each part may be seen as a holographic representation of the whole.

3. Convenience for editors and peer-reviewers. Over 3 million manuscripts are submitted to journals every year (Report of the Science and Technology Committee, 2011), imposing a considerable burden on their editors and peer-reviewers. The IMRAD format with its strict rules is helpful in providing a coarse sieve for selecting works for subsequent peer-review.

4. Convenience for citation engines. In an age of burgeoning information, an increasing number of parameters are being processed not by humans, but by machines. Standardised forms used to present information allow global citation and scientometric indexes (such as Scopus or Web of Science) to effectively analyse 
connections between scholarly papers (i.e. citations in later work based on earlier articles), thus providing a tool for measuring research performance.

Despite all the above-mentioned benefits, IMRAD is increasingly criticised for its rigidity, over-simplicity and over-standardisation. From a phenomenological perspective, it could not be any other way, since the only possible outcome of blindly surrendering to the They is mediocrity. Indeed, while the future of science as a human activity has been shown to depend on creativity (Hadzigeorgiou, 2012), academic writing is becoming more and more rigid - not only at the macro-level (compositional structure), but also on the micro-level (semantic units). As a consequence of such rigid enframing, many papers in natural sciences are virtually indistinguishable from one another, varying only in terms of the numerical information so presented. This fact even led some researchers to make a bold prediction: we may soon witness the end of scientific articles, which will be substituted by "ontologies" (IMRAD carried to an extreme) (West, 2016): such an outcome would mark a kind of technological singularity moment at which the They is seen to triumph over the authentic self of individual researchers. Researchers will no longer be required to create texts; it will be sufficient to simply upload properly formatted information into pre-assigned spaces.

Being a reflection of the world-view of the They, IMRAD may be seen as increasingly stifling spontaneous narrativity due to the They being highly intolerant of creativity as such. Perhaps it is for this reason that any interested researcher can find various IMRAD templates or "cheat-sheets" on the Internet that can be used to create a paper ${ }^{5}$. In conformance with the current state of affairs in science, most editors expect to see papers written in this format; there have even been cases when some clearly non-scientific papers were published simply because they had the external appearance of IMRAD papers (Bohannon, 2013). It can be concluded that, due to the supremacy of technological rationality in general and such conformist modes of existence in particular, IMRAD has burgeoned from an optional instrument of convenience into a self-sufficient value, dominating and even domineering the world of academic communication.

The widespread distribution of technologies such as IMRAD can also be analysed from the perspective of the process of bureaucratisation. Max Weber showed that increases in the size and scope of every social sector are associated with the implementation of a bureaucratic principle (Weber, 1922) as a response to the need for rationalisation and ordering of any human activity. This - according to Weber, inevitable - process is characterised by greater division of labour, standardisation, hierarchy and decentralisation. The growth of organised science (Adams et al., 2005; Wuchty et al., 2007) and its increasing massification is likely to also result in its greater bureaucratisation. Indeed, as it has been conclusively shown (Walsh \& Lee, 2015; Coccia, 2009), science as a human activity is becoming more: (a) hierarchical, with multiple levels of supervision appearing (growth of administrative structures, such as FANO and VAK in Russia); (b) decentralised, which means that those lower in

${ }^{5}$ See, e.g. https://www.cmu.edu/gcc/handouts/IMRD\%20with\%20Examples.pdf 
the hierarchy can make independent decisions though formally approved by those higher in the organisation (which is demonstrated in Russia by reduced governmental budgetary funding for research); (c) highly labour-divided (Popov et al., 2017), with every researcher in a research team performing her narrow circle of responsibilities (e.g. some researchers in the natural sciences); and (d) standardised, meaning that all the work is governed by strictly specified rules and fixed procedures (IMRAD, reports, requirements for applicants for scientific degrees, scientometric indicators measuring research performance, etc.).

To a lesser or greater extent, all these dimensions of bureaucratisation can be also considered as a result of the enframing of the sphere of academic science by the They for its own convenience. As was previously mentioned, the They mostly acts through such existential characteristics as distantiality, averaging and levelling down, imposing conformity as a mode of existence to everybody who gives up responsibility for his own Dasein and instead plays by the rules of the scientised world-view. Namely, these characteristics manifest themselves in science in terms of alienation (distantiality) of a researcher's personality from the results of his work; disregard (averaging) of any personal impact and achievements in order to bring to the fore the part of bureaucratic structures and self-producing machines (West, 2016); standardisation (levelling down), which appears in a reduction to a common denominator of everything beyond established standards. Therefore, it can be concluded that, with conformity being a mode of existence, science has become a highly-bureaucratised activity, whose performance is entirely dependent on how effectively such technological instruments, e.g. as IMRAD, are used. It should be mentioned that IMRAD is just one illustration; among other technologies that disseminate the academic others into the They are global scientometric indexes, systems of academic ratings, rankings and tenure, etc.

Taken all the above mentioned into account, the next step would be to look at how people respond to these transformations. This idea seems to be consistent with the concept of the bureaucratic personality (Merton, 1940; Thomson, 1961; Bozeman \& Rainy, 1998), which was developed to capture the changing nature of personality in the context of an environment that is becoming more and more bureaucratic. Increasing specialisation and division of labour, along with such benefits as increasing rationality and a movement from dilettantism to professionalism, eventually leads to the pathologic distortions - or "bureaupathologies" - of Weberian virtues (Thomson, 1961), including alienation and impersonal attitude, loss of creativity and enthusiasm, mechanistic behaviour and lower personal responsibility for the result - all qualities whose overall contribution to knowledge generation may be suspected to be negative. The underlying reason for all such responses was shown to be the loss of personal security (Thomson, 1961). An impressive list of 175 bureaupathologies was given by Caiden (1991), who insisted that these "systemic shortcomings" (Caiden, 1991) are the result of forcing individuals within an organisation to conform to extensive norms and rules.

In other words, conformist behaviour becomes the strategy of choice used by the bureaucratic personality to avoid penalties. This is particularly so in science, 
since contemporary researchers are expected to conform to the established order: publish in journals indexed in international databases, conduct experiments that fall into mainstream frameworks, promote their research within academia to get more citations, establish a rapport with scientific administrators to obtain stable funding and position, etc. It comes as no surprise then that technological instruments become an undisputable value, providing a means for achieving conformity - and, consequently, "social survival" (Fisk, 2016).

There seems to be an interdependent relationship between the concepts of technologised consciousness (as described following Heidegger's phenomenological theory) and bureaucratic personality. Significantly, these concepts helped us to analyse the transformations that the contemporary human activity of science is undergoing, as well as to take a closer look at the instruments that researchers as bearers of technologised consciousness apply nowadays to survive in a highly-enframed and bureaucratised environment.

\section{Conclusion}

In this paper, our purpose was to investigate intricate connections between science as a transforming human activity, researchers as active producers of such transformations and society as a whole.

We have shown that the contemporary social reality features such distinct processes as the penetration of science into all social spheres (scientisation) and the associated massification of science as a human activity. These trends, like any social process involving growing complexity, are accompanied by increased bureaucratisation, whose function is to organise and regulate the social order by establishing norms, restrictions and penalties. The bureaucratic mechanism exerts a definite pressure on researchers, forcing them to search for appropriate approaches for dealing with the more challenging environment. As has been shown, conformism frequently becomes the strategy of choice, since imitating socially approved behaviour can lead to stability and success.

However, we have also shown that conformism is merely a representation of a more ontologically loaded phenomenon - conformity - whose nature we attempted to reveal using Heidegger's phenomenological approach. In the initial analytical step, we looked at technological rationality as a modern state of being and showed how technologies are often transmuted into teleologies. Thus, technologies become part of human consciousness. Such a technologised consciousness can properly function only within a specific configuration, which Heidegger calls enframing. In modern science, this enframing, which alters human orientation to the world, takes the form of conformity and becomes the primary mode of existence.

Conformity as a phenomenon inherent to modern science has a number of societal effects, which can be predicted to drive massive social transformations. These effects can be considered at various levels: within a scientific community, a particular society, and / or at a global level. Their detailed analysis should become a focus of another investigation; however, let us here briefly draft some possible outcomes of 
the abovementioned trends. It should be noted that these outcomes can be both of a positive and negative character. The results of conformity within a scientific community may involve lower creativity and responsibility for the product, increased focus on empirical methods of research, accumulation of empirical results that will never be theoretically examined and discrimination against non-western research approaches. However, conformity, with its clearly formulated rules and standardised procedures, also serves to make such a previously elite form of human activity as science accessible to ordinary people.

Within a particular society, conformity is manifested when people uncritically absorb standards imposed by technologised consciousness. An example is the emphasis of many societies on the goals of material prosperity, resulting in greater concern with the technological instruments conducing to such an outcome. At a global level, conformity can be analysed from the standpoint of non-western communities conforming to western standards of life through borrowing from the western scientific world picture. Thus, in aiming to be included in the international citation indexes of Scopus and Web of Science, many Russian journals face the need to introduce substantial changes in almost all aspects of their work, from the traditional model of peer-review to the selection of content.

\section{Acknowledgements}

The authors would like to thank the contributions of the anonymous reviewers, whose comments resulted in the present, improved text.

\section{References}

Adams, J., Black, G., Clemmons, J. R., Stephan, P. E. (2005). Scientific teams and institutional collaborations: evidence from U.S. universities, 1981-1999. Research Policy, 34, 259-285.

Alexandre, V., Gasparski, W. (2000). The Roots of Praxeology: French Action Theory from Bourdeau and Espinas to Present Days. New Brunswick, NJ: Transaction Publishers.

Ash, S. (1955). Opinions and social pressure. Scientific American, Vol. 193, No. $5,31-35$.

Brett, P. (1994). A genre analysis of the results section of sociology articles. English for Specific Purposes, 13(1), 47-59.

Brey, P. (2000). Technology as Extension of Human Faculties. Metaphysics, Epistemology, and Technology. In C. Mitcham (ed.) Research in Philosophy and Technology, Vol 19. London: Elsevier/JAl Press.

Bohannon, J. (2013). Who's afraid of peer review? Science, No. 6154 (342), 60-65. 
Bozeman, B., Rainey, H. (1998). Organizational rules and the bureaucratic personality. American Journal of Political Science, 42(1), 163-189.

Caiden, J. (1991). What really is public maladministration? Public Administration Review, Vol. 50, 525-535.

Coccia, M. (2009). Bureaucratization in public research institutions. Minerva, 43, $31-50$.

Cooper, C. (2016). Citizen science: How ordinary people are changing the face of discovery. New York: The Overlook Press.

Crozier, M. (1964). The Bureaucratic Phenomenon. London: Tavistock Publications.

Dekker, S. (2014). The bureaucratization of safety. Safety science, Vol. 70, 348357. DOI: 10.1016/j.ssci.2014.07.015

Descartes, R. (2004). A Discourse on Method: Meditations and Principles. London: Orion Publishing Group.

Dusek, V. (2006). Philosophy of Technology: an Introduction. Malden, MA: Blackwell Publishing.

Ellul, J. (1964). The Technological Society. New York: Vintage Books.

Etzkowitz, H. (1983). Entrepreneurial scientists and entrepreneurial universities in American academic science. Minerva, 21, 198-233.

Fisk, M. (2016). Ethics and social survival. New York: Routledge.

Fromm, E. (1965). Escape from freedom. New York: Henry Holt and Company.

Gross, A., Harmon, J., Reidy, M. (2002). Communicating science: The scientific article from the $17^{\text {th }}$ century to the present. Oxford: Oxford University Press.

Hackett, E. (1990). Science as a vocation in the 1990 - the changing organizational culture of academic science. Journal of Higher Education, 61, 241-279.

Hadzigeorgiou, Y., Fokialis, P., Kabouropoulou, M. (2012). Thinking about creativity in science education. Creative education, Vol. 3, 5, 603-611.

Heidegger, M. (1962). Being and Time. (J. Macquarrie and E. Robinson, trans.). Malden, MA: Blackwell Publishers. 
Heidegger, M. (1977). The Age of the World-Picture. (W. Lovitt, trans.) New York \& London: Garland Publishing. 115-155.

Heidegger, M. (1977). The Question Concerning Technologies. (W. Lovitt, trans.) New York \& London: Garland Publishing. 3-36.

Heidegger, M. (1977). Science and Reflection. (W. Lovitt, trans.) New York \& London: Garland Publishing. 155-182.

Hopkins, A., Dudley-Evans, T. (1988). A genre-based investigation of the discussion sections in articles and dissertations. English for Specific Purposes, 7(2), 113-122.

Horkheimer, M., Adorno, T. (2002). Dialectic of Enlightenment. Stanford: Stanford University Press.

Jünger, F. G. (2010). Die Perfektion der Technik [The Perfection of Technology]. Göttingen: Hubert \& Co.

Kanoksilapatham, B. (2005). Rhetorical structure of biochemistry research articles. English for Specific Purposes, Vol. 24, 269-292.

Kintsch, W. (1998). Comprehension: A paradigm for cognition. Cambridge, UK: Cambridge University Press.

Marcuse, H. (1982). "Some Social Implications of Modern Technology". In Andrew Arato and Eike Gebhardt (eds.) The Essential Frankfurt School Reader. New York: Continuum. 138-162.

Marcuse, H. (2002). One-Dimensional Man. London \& New York: Routledge.

Marx, K. (1977). Capital: a Critique of Political Economy. Vol. 1. Book 1. Moscow: Progress Publishers.

Merton, R. (1940). Bureaucratic structure and personality. Social Forces, Vol. 18, No. $4,560-568$.

Merton, R. (1938). Social structure and anomie. American Sociological Review, Vol. 3, Issue 5, 672-682.

Mitcham, C. (1994). Thinking through Technologies: the Path between Engineering and Technology. Chicago \& London: University of Chicago Press.

Nadal, P. (2010). Heidegger's Critique of Modern Technology: On "The Question Concerning Technology" Retrieved from https://belate.wordpress.com/2010/07/12/ heidegger-modern-technology 
Nadal, P. (2013). What is Modernity? Retrieved from https://belate.wordpress. com/2013/03/03/what-is-Modernity/

Nadal, P. (2012). What is World: On Boredom, Modernity, and World in Heidegger. Retrieved from https://belate.wordpress.com/2012/02/29/what-is-world-heidegger

Popova, N., Beavitt, T. (2017). English as a Scientific Communication Device: Linguistic Imperialism or Interlingua? Integration of Education, Vol. 21, No. 1, 54-70. DOI: 10.15507/1991-9468.086.021.201701.054-070

Popov, E., Popova, N., Biricheva, E., Kochetkov, D. (2017). A goal-oriented approach to performance assessment of research teams. University management: Practice and Analysis, Vol. 23, No. 3, 6-18.

Prince, D. (1963). Little science, big science. New York: Columbia University Press.

Report of the House of Commons Science and Technology Committee. (2011). Peer review in scientific publications. Vol. 1. London, UK: House of Commons.

Salazar, C., Bestard, J. (2015). Religion and Science as Forms of Life: Anthropological Insights into Reason and Unreason. Oxford \& New York: Berghahn Books.

Schwab, K. (2016). The Fourth Industrial Revolution. Geneva, Switzerland: World Economic Forum.

Skinner, B. (1976). About Behaviorism. New York: Vintage Books.

Smith, E., Winterhalder, B. (1992). Evolutionary ecology and human behavior. New York: Aldine de Gruyter.

Sollaci, L., Pereira, M. (2004). The introduction, methods, results and discussion (IMRAD) structure: a fifty year survey. Journal of the Medical Library Association, 92(3), 364-371.

Swales, J. (1990). Genre analysis. Cambridge: Cambridge University Press.

“Technology versus Man” (1949). Manas Reprint, Vol. 2, No. 26. 1-13.

Thompson, V. (1961). Modern Organization. New York: Knopf.

Walsh, J., Lee, Y. (2015). The bureaucratization of science. Research Policy, 44, 1584-1600.

Weber, M. (1978). Economy and Society. Berkeley, CA: University of California Press. 
West, R. (2016). The end of scientific articles as we know them? Journal of clinical epidemiology, Vol. 70, 276. DOI: 10.1016/j.jclinepi.2015.06.017

Wuchty, S., Jones, B., Uzzi, B. (2007). The increasing dominance of teams in the production of knowledge. Science, 316, 1036-1039. 